RESEARCH PAPER

\title{
Changes in population attitudes about where smoking should not be allowed: California versus the rest of the USA
}

\author{
E A Gilpin, L Lee, J P Pierce
}

Tobacco Control 2004;13:38-44. doi: 10.1136/tc.2003.004739

See end of article for authors' affiliations

.....................

Correspondence to: John P Pierce, PhD, Cancer

Prevention and Control Program, University of California, San Diego, 9500 Gilman Drive, 0645 La Jolla, CA 92093-0645, USA; ippierce@ucsd.edu

Received 30 May 2003 Accepted 2 October 2003
Background: The decade long California Tobacco Control Program is unique to the nation in its duration, emphasis, and level of funding. Programme emphasis is on changing social norms about smoking as a means to discourage smoking and thus reduce the harmful health effects of tobacco to the population. Methods: Data from the 1992-93, 1995-96, and 1998-99 Tobacco Use Supplements to the national Current Population Survey ( $\mathrm{n}>175000$ each period) were used to examine changes in norms regarding where smoking should "not be allowed at all" in both California and in the rest of the USA. Venues queried were restaurants, hospitals, work areas, bars, indoor sports venues, and indoor shopping malls. Results: There were substantial increases in the percentages of the adult population (18+ years) stating that smoking should not be allowed in the venues queried in California by 1998-99 compared to 1992-93; only modest increases were observed in the rest of the USA. In fact, for most venues, the percentages for the rest of the USA were lower in 1998-99 than in California in 1992-93. Further, the percentage increase over this period in respondents stating that smoking should not be allowed in four or more of the six venues was $30 \%$ in California and $23 \%$ in the rest of the USA. The most dramatic percentage increase in California occurred among current smokers (93\%).

Conclusions: A strong, comprehensive tobacco control programme such as California's can influence population norms, including those of smokers, with respect to where smoking should not be allowed.
$\mathrm{T}$ he aim of public health tobacco control efforts is to reduce morbidity and mortality caused by preventable smoking related diseases. ${ }^{1}$ To accomplish this goal, smoking behaviour must be curtailed by encouraging smokers to quit and discouraging adolescents from initiating smoking. While some tobacco control efforts focus directly on specific smoking cessation and teen prevention programmes, a more comprehensive programme approach also seeks to change population attitudes and norms about smoking in general. ${ }^{12}$ In a society where smoking is not viewed as an acceptable activity, fewer people will smoke, and as fewer people smoke, smoking will become even more marginalised.

For over a decade, the comprehensive California Tobacco Control Program has placed particular emphasis on changing social norms about smoking as a means to accomplish its goal. ${ }^{2}$ This programme is unique in the nation with respect to its duration and level of funding. One of the major successes of California's programme is the growing population acceptance of smoking restrictions. In 1995, most indoor California workplaces were mandated to be smoke-free, and in January 1998 the law was extended to cover the remaining ones: clubs/bars and gaming rooms. More importantly, between 1993 and 1999, the percentage of Californians who no longer allowed smoking in their own homes increased from $37.6 \%$ to $73.7 \%$, and by 1999 nearly half $(48.6 \%)$ of all California smokers reported that their homes were smoke-free. ${ }^{3}$

While smoking restrictions are for the protection of the health of non-smokers (including children) from the dangers of secondhand smoke, ${ }^{4-8}$ they also indicate the general populations' tolerance or lack of tolerance regarding smoking. Thus, the populations' beliefs about where smoking should not be allowed can be considered an indicator of its attitudes toward smoking in general. Tracking changes in these attitudes over time can provide a measure of progress toward reaching the ultimate objective of a smoke-free society.
In this article, we used data from large population based surveys to compare California with the rest of the USA with respect to attitudes about where smoking should not be allowed at all. The Current Population Surveys of 1992-93, 1995-96, and 1998-99 included a Tobacco Use Supplement that asked a series of six questions concerning settings where smoking should be allowed in all areas, in some areas, or not allowed at all. We tabulated the "not allowed at all" responses for California and the rest of the USA, and present trends across the three survey periods according to demographic subgroups, whether or not the respondent is subject to workplace or home smoking bans, and respondent smoking status.

\section{METHODS}

\section{Data source}

The national Current Population Survey (CPS) periodically includes a special Tobacco Use Supplement (TUS), which was the source of the data for this analysis. The CPS is a continuous survey (over 56000 households/month) conducted by the US Bureau of the Census, primarily to monitor labour force indicators for the civilian non-institutionalised US population age 15 years and older. The complete CPS methodology is published elsewhere. ${ }^{90}$ Briefly, the CPS includes a probability sample, based on a stratified sampling scheme of clusters of four neighbouring households identified from the most recent decennial census, updated building permits, and other sources. All strata are defined within state boundaries, and the sample is allocated among the states so that state specific estimates can be computed.

Abbreviations: CPS, Current Population Survey; TUS, Tobacco Use Supplement 

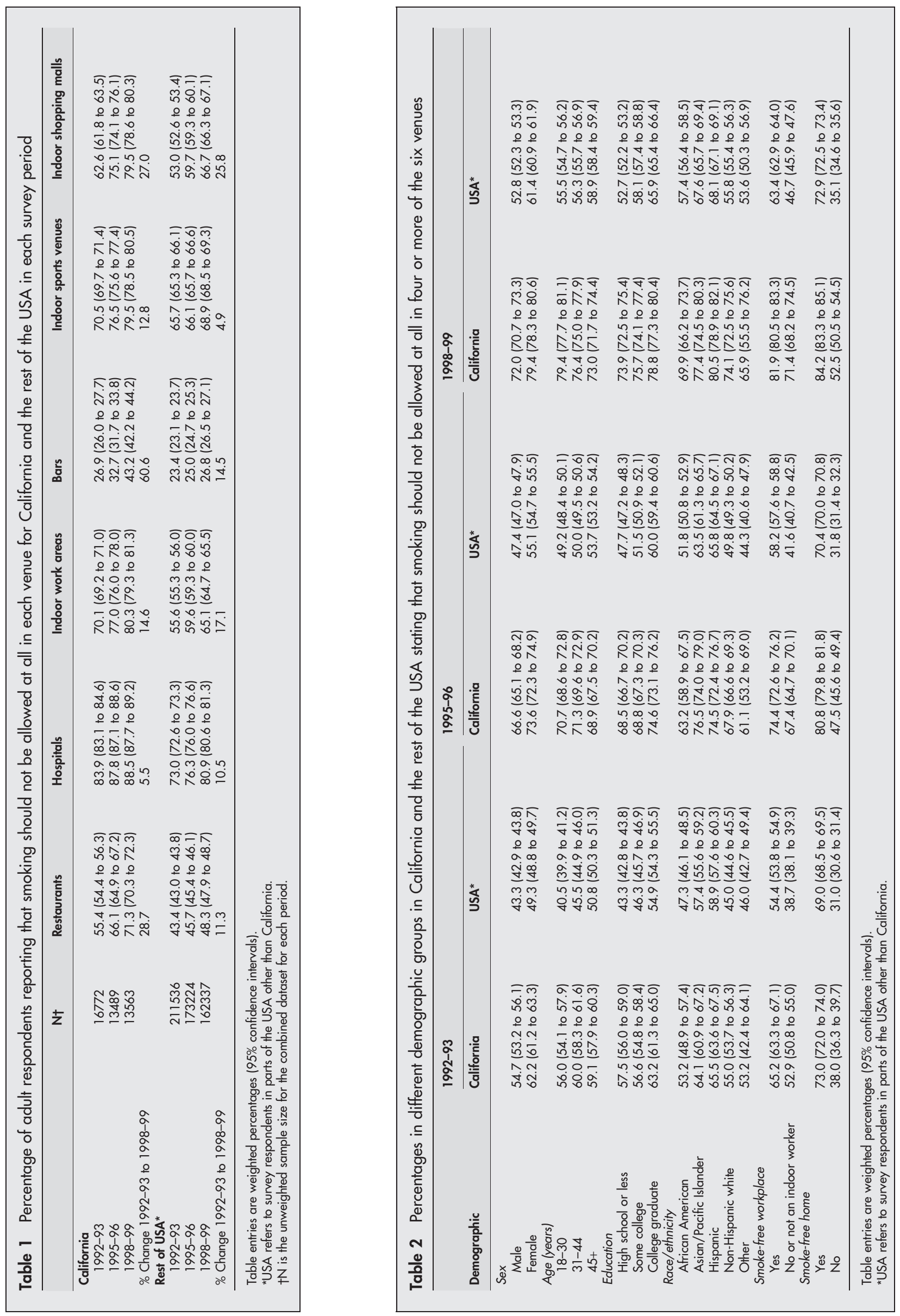


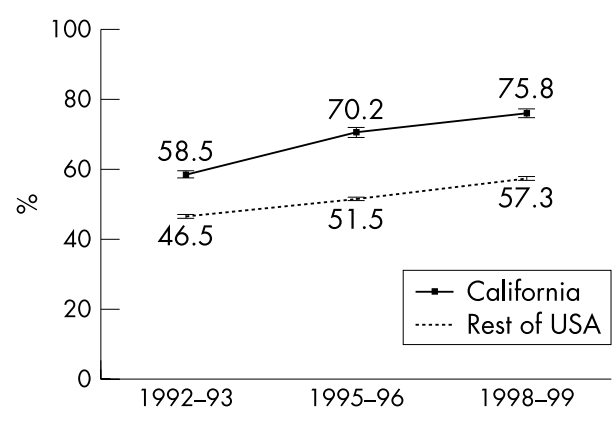

Figure 1 Percentage of respondents in California and in the rest of the USA who reported that smoking should not be allowed at all in four or more of six venues (restaurants, hospitals, work areas, bars, indoor sports venues, and indoor shopping malls) in cross-sectional surveys conducted in 1992-93, 1995-96, and 1998-99.

TUS were included for the months of September, January and May in 1992-93, 1995-96, and 1998-99. For the present study, data on adults age 18 years and older from the three months in each period were analysed. The TUS was developed by the National Cancer Institute staff and pretested by trained Bureau of the Census interviewers before implementation.

\section{Questions analysed Venues}

The TUS asked respondents if smoking should be allowed in "all areas, in some areas, or not allowed at all" in six settings: (1) restaurants, (2) hospitals, (3) indoor work areas, (4) bars and cocktail lounges, (5) indoor sports venues, and (6) indoor shopping malls. The responses to these questions were examined individually, and as a combined variable (answered "not allowed at all" to four or more of the six venues).

\section{Demographics}

The 4+ measure was examined overall and according to the respondents' age group (18-30, 31-44, 45+ years), sex, education level (high school or less, some college, college graduate), and race/ethnicity (non-Hispanic white, Hispanic, African American, Asian/Pacific Islander, other).

\section{Smoking status}

We also examined the $4+$ metric by smoking status. All respondents were asked: "Have you smoked at least 100 cigarettes in your entire life?"; those who answered yes were further asked, "Do you now smoke cigarettes every day, some days, or not at all?" Current smokers were defined as those who reported smoking at least 100 cigarettes in their lifetime and said they now smoked everyday or some days. Former smokers also had to report smoking at least 100 cigarettes in their lifetime, but say they now smoke not at all. Never smokers are those who smoked fewer than 100 cigarettes in their lifetime.

\section{Smoking restrictions}

Finally, we tabulated the results by whether or not subjects reported smoking bans in their workplaces or homes.

After determining that respondents worked outside the home, were not self-employed, and worked in an indoor setting, they were asked: "Does your place of work have an official policy that restricts smoking in any way?". Those who answered "yes" were then asked: "Which of these best describes your place of work's smoking policy for work areas?" and "Which of these best describes your place of work's smoking policy for indoor public or common areas such as lobbies, rest rooms, and lunch rooms?". The descriptive statements were: (1) "Not allowed in any", (2) "Allowed in some areas", and (3) "Allowed in all areas". A respondent who answered "Not allowed in any areas" to both questions was considered to work in a smoke-free workplace. All other respondents, including those not employed, self employed, outdoor workers, and those with missing values for any of the above questions were considered not subject to a smoke-free workplace.

Respondents were asked about smoking restrictions in their homes with the question: "Which statement best describes the rules about smoking in your home?". The statements were: (1) "No one is allowed to smoke anywhere", (2) "Smoking is allowed in some places or at some times", or (3) "Smoking is permitted anywhere". Only respondents who agreed with the first statement were considered to live in smoke-free homes.

\section{Statistics}

The CPS include special weights for self respondents so that population estimates can be computed. Base weights reflect the sampling probability and are further ratio adjusted using census totals for demographic groups, region, and state. This procedure allows state specific population estimates to be computed. Because of the complex sampling design, the Bureau of the Census also provides a set of replicate weights for variance estimation purposes. We used Fay's method of balanced repeated replication from the statistical package WesVar PC to obtain 95\% confidence intervals for all estimates reported in the text, tables, and figures. ${ }^{11}$

Wes Var PC also includes a logistic regression routine that we used to examine the association of period (1992-93, 1995-96, 1998-99), region (California versus the rest of the USA), demographic variables, and other factors with respondents' indicating that smoking should not be allowed in four or more of the six venues. To verify the observation that California changed more than the rest of the USA, after adjusting for demographic characteristics, an interaction term was included for region and period. Additional analyses investigated other interactions suggested by the demographic tabulations. For these analyses, terms were included in the model for being a Californian and having the characteristic of interest (for example, female, smoker, etc), and for being a Californian in 1998-99 who had the characteristic.

\section{RESULTS}

\section{Individual venues}

Table 1 shows the percentages of adult Californians and those in the rest of the USA answering that smoking should not be allowed at all in the various venues in the three survey periods. Hospitals were the venue for which the greatest percentages of respondents, both in California and nationally, thought smoking should not be allowed. Interestingly, indoor sports venues garnered second place nationally, but indoor work areas showed slightly higher percentages in California for 1995-96 and 1998-99. It is also interesting that indoor shopping malls showed greater percentages than restaurants. In fact, only bars showed lower percentages than restaurants that smoking should not be allowed.

In the rest of the USA (excluding California), the venues showing the greatest percentage change in respondents stating that smoking should not be allowed over the survey periods were indoor work areas (percentage change 17.1\%) and indoor shopping malls $(26.8 \%)$. Californians showed substantial percentage increases for all venues except for hospitals, which already were at very high levels in 1992-93. By 1998-99, 43.2\% of Californians thought smoking should not be allowed at all in bars, a 60.6\% increase from 1992-93. 


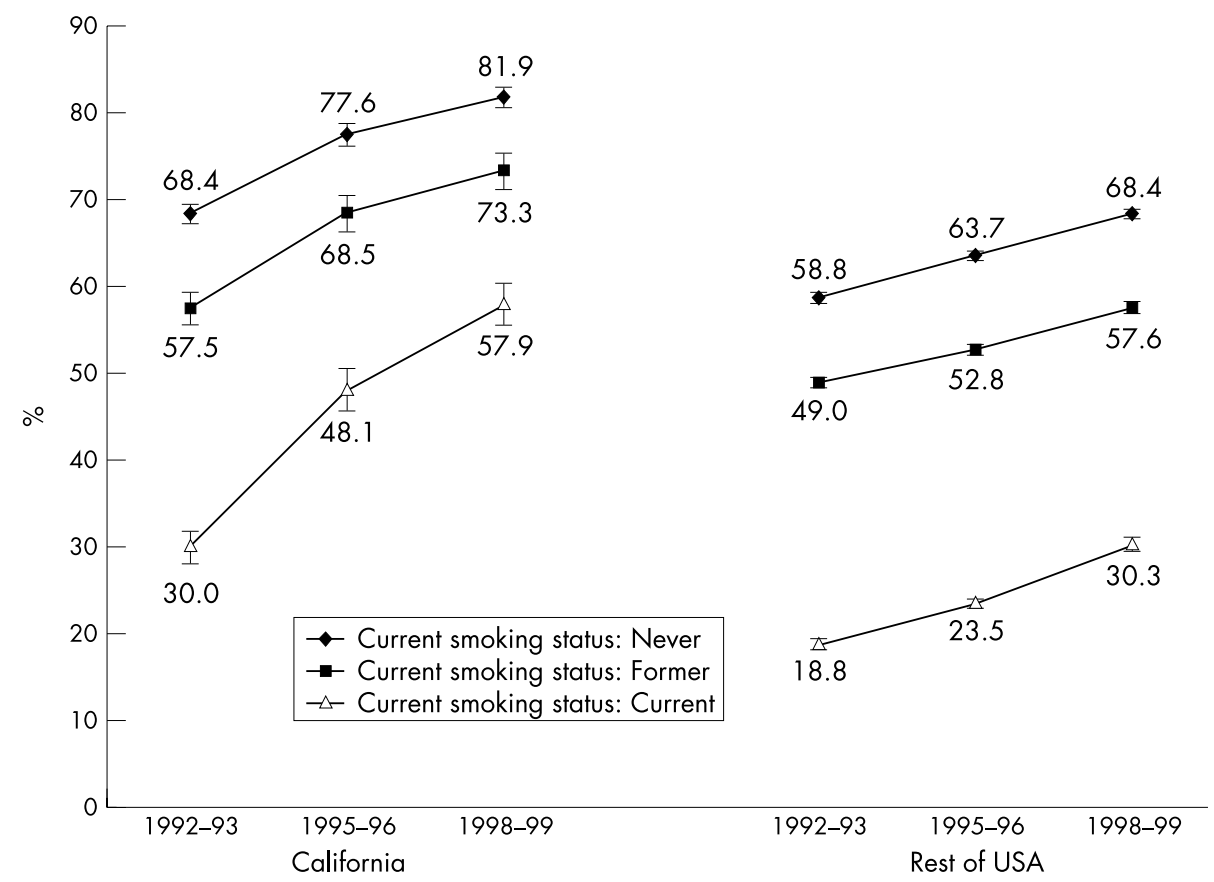

Figure 2 Percentage of respondents in California and in the rest of the USA who reported that smoking should not be allowed at all in four or more of six venues (restaurants, hospitals, work areas, bars, indoor sports venues, and indoor shopping malls) in crosssectional surveys conducted in 1992$93,1995-96$, and 1998-99 by current smoking status (current, former, never).

Table 3 Multivariate association of a high level of support for non-smoking venues (at least 4) with period (1992-93, 1995-96, 1998-99), region (California versus the rest of the USA), and the demographic and other variables

\begin{tabular}{|c|c|c|}
\hline Variable & Adjusted ${ }^{*}$ odds ratio & $95 \%$ confidence interval \\
\hline \multicolumn{3}{|l|}{ Period } \\
\hline $1992-93$ & 1.00 & \\
\hline $1995-96$ & 1.11 & $(1.08$ to 1.15$)$ \\
\hline 1998-99 & 1.26 & (1.22 to 1.31 ) \\
\hline \multicolumn{3}{|l|}{ Region } \\
\hline USA minus California & 1.00 & \\
\hline California & 1.50 & (1.42 to 1.58$)$ \\
\hline \multicolumn{3}{|l|}{ Interaction (region $\times$ period) } \\
\hline Otherwise & 1.00 & \\
\hline California in 1998-99 & 1.49 & $(1.34$ to 1.66$)$ \\
\hline \multicolumn{3}{|l|}{ Sex } \\
\hline Male & 1.0 & \\
\hline Female & 1.28 & (1.25 to 1.31$)$ \\
\hline \multicolumn{3}{|l|}{ Age (years) } \\
\hline $45+$ & 1.00 & \\
\hline $31-44$ & 0.82 & $(0.80$ to 0.84$)$ \\
\hline $18-30$ & 0.72 & (0.69 to 0.74$)$ \\
\hline \multicolumn{3}{|l|}{ Education } \\
\hline College graduate & 1.00 & \\
\hline Some college & 0.97 & (0.94 to 0.99$)$ \\
\hline High school or less & 0.90 & $(0.88$ to 0.93$)$ \\
\hline \multicolumn{3}{|l|}{ Race/ethnicity } \\
\hline Non-Hispanic white & 1.00 & \\
\hline Asian/Pacific Islander & 1.22 & (1.15 to 1.31$)$ \\
\hline Hispanic & 1.48 & (1.40 to 1.56$)$ \\
\hline African American & 1.05 & (1.01 to 1.09 ) \\
\hline Other & 1.09 & (0.95 to 1.24$)$ \\
\hline \multicolumn{3}{|l|}{ Smoke-free workplace } \\
\hline No, or not an indoor worker & 1.00 & \\
\hline Yes & 1.57 & (1.54 to 1.60$)$ \\
\hline \multicolumn{3}{|l|}{ Smoke-free home } \\
\hline No & 1.00 & \\
\hline Yes & 3.29 & (3.22 to 3.34 ) \\
\hline \multicolumn{3}{|l|}{ Smoking status } \\
\hline Never & 1.00 & \\
\hline Former & 0.73 & $(0.71$ to 0.75$)$ \\
\hline Current & 0.35 & $(0.34$ to 0.36$)$ \\
\hline
\end{tabular}


Large percentage increases were also observed for restaurants $(28.7 \%)$ and indoor shopping malls $(26.8 \%)$.

To summarise these trends, fig 1 gives the percentages of respondents who stated that smoking should not be allowed at all in four or more of the individual settings in each of the survey periods for California and the rest of the USA. In 1992-93, Californians showed a higher level of support for smoke-free settings than people in the rest of the USA did in 1998-99. Furthermore, despite initially higher levels, Californians showed a larger change in attitudes than people in the rest of the USA. The percentage change in Californians indicating that smoking should not be allowed in four or more venues was $30 \%$, but it was only $23 \%$ for the rest of the USA.

\section{Demographics and other characteristics}

Table 2 summarises the attitudes of Californians and those in the rest of the USA concerning where smoking should not be allowed at all in four or more venues by different demographic subgroups over the three survey periods. In all survey periods, females were more likely than males to state that smoking should not be allowed in four or more of the venues. However, the sex gap tended to widen, more so in the rest of the USA. The percentage increase between 1992-93 and 1998-99 was similar for both sexes (about 33\%) in California, but greater for females $(30.8 \%)$ than males $(25.2 \%)$ in the rest of the USA. Whereas younger adults were less likely than older adults to agree that four or more of the venues should be smoke-free in 1992-93, they showed a higher percentage change by 1998-99 (45.8\% in California and $38.9 \%$ in the rest of the USA), so that there was little difference by age in California in the later period.

In 1992-93, both in California and in the rest of the USA, there was a direct relation between thinking smoking should not be allowed in four or more venues and educational attainment. However, by 1998-99, this difference had disappeared in California, but still persisted to about the same degree in the rest of the USA. A similar pattern was observed among racial/ethnic groups. In 1992-93, Asians and Hispanics showed higher levels of support than other racial/ ethnic groups for smoke-free venues in both California and the rest of the USA. However, by 1998-99 the racial/ethnic differences were largely absent in California but persisted in the rest of the USA.

Both in California and the rest of the USA, persons working in smoke-free workplaces were more likely to support at least four smoke-free venues in all survey periods. However, by 1998-99 the gap closed to a much greater degree in California than in the rest of the USA. The percentage increase in support for California adults not covered by a smoking ban was $37.7 \%$ compared to $25.2 \%$ in workers covered; in the rest of the USA these percentage increases were $21.3 \%$ and $17.7 \%$, respectively. In 1992-93, $54.5(2.8) \%$ of California's indoor workers worked in a smoke-free indoor workplace and this increased to 76.4 (1.3)\% by 1998-99; comparable percentages for the rest of the USA were 43.9 (1.4)\% and $67.4(0.5) \%$, respectively.

Having a smoke-free home appeared to influence attitudes about where smoking should not be allowed more than having a smoke-free workplace. Persons with smoke-free homes were considerably more likely to state that smoking should not be allowed in at least four venues than those without smoke-free homes. The level of support was higher for those with smoke-free homes than for any other subgroup examined. However, by 1998-99, Californians without smokefree homes showed a very large percentage increase in support (without 53.5\% v with 15\%), which served to narrow the support gap compared to respondents with smoke-free homes. As for workplaces, more Californians

\section{What this paper adds}

Comprehensive tobacco control programmes seek to change population social norms about smoking as one step in reducing future adverse health effects of tobacco. One indication of society's views about smoking is where people think smoking should not be allowed.

This paper presents trends from large population surveys in the 1990s in the percentages of respondents saying that smoking should not be allowed at all in a number of settings. In California, with a longstanding, comprehensive tobacco control programme, there were greater increases in support for smoke-free venues, including among smokers, than among respondents in the rest of the USA.

had smoke-free homes in 1998-99 (58.1 (1.6)\%) compared to 1992-93 (73.1 $(1.1 \%))$, and this was true for the rest of the USA as well (1998-99: $58.6(0.3) \%$; 1992-93: $40.4(1.1) \%)$.

As would be expected, smokers were less likely to favour smoking bans than non-smokers or never smokers (fig 2). California's smokers, however, showed a large increase in their support for smoke-free venues. Between 1992-93 and 1998-99, the percentage increase was $93 \%$ for the $4+$ measure, compared to $27 \%$ for former smokers and $20 \%$ for never smokers. These increases in the rest of the USA were $61 \%, 18 \%$, and 16\%, respectively. In 1998-99, California's smokers showed levels of support for bans similar to never smokers in the rest of the USA in 1992-93.

\section{Multivariate analysis}

Table 3 shows the results of a logistic regression analysis where the dependent variable was the response that smoking should not be allowed at all in four or more venues, and the independent variables were survey period (1992-93, 1995-96, 1998-99), region (California versus the rest of the USA), demographics, report of a smoke-free workplace, report of a smoke-free home, smoking status, and an interaction between region and period that tests for an added effect by 1998-99 for Californians. The results of the multivariate analyses are consistent with the percentages in table 2, even after adjusting for the other variables in the analysis. The factors most related to level of support for smoke-free venues were living in a smoke-free household and smoking status. Other factors also highly related were working in a smokefree workplace, being of Hispanic origin, and being a Californian. There was an additional effect for Californians in 1998-99 (interaction) beyond the main effects for period and region, confirming that Californians had advanced further by 1998-99. If the trends over time (fig 1) were parallel for California and the rest of the USA, the interaction term would not have been significant.

Additional multivariate analyses included selected three way interaction terms suggested by the data in table 2 . These analyses included the California-time period interaction described previously and an additional effect for the group of interest in 1998-99. A significant interaction for this term indicates that the group of interest changed to a different extent than the others. The results described below are not included in table 3. Californians 18-30 years of age in 199899 showed a significant added effect. In separate analyses, the same was true for California females, and for Californians who did not live in a smoke-free home. An analysis that did not show an added effect for Californians in 1998-99 examined those with no college experience. Finally, there was a significant additional effect for California smokers, and for California smokers in 1998-99, indicating their high degree of change in agreement with smoking restrictions. 


\section{DISCUSSION}

Compared to the rest of the USA, Californians exhibited a considerable change in attitude about where smoking should not be allowed between 1992-93 and 1998-99. In 1992-93, Californians showed higher levels in population attitudes regarding where smoking should not be allowed than the rest of the USA did in 1998-99. This change in societal attitudes in California likely reflects the influence of its comprehensive tobacco control programme.

By 1992-93, California was several years into its tobacco control programme and had probably already progressed to some degree. Alternatively, Californians may have always been somewhat more inclined to support smoke-free settings. A national survey conducted in $1986^{12}$ showed that persons in the western region of the USA, many of whom are Californians, were slightly more likely to report at least some type of restriction on smoking in the workplace than people in the rest of the USA (50\% $v 42 \%)$. However, report of smoke-free workplaces, smoky work areas, and preference for being seated in non-smoking sections of restaurants did not differ by region. Thus, the results of the present study suggest that comprehensive and coordinated tobacco control programmes elsewhere in the USA could have an effect on population norms similar to that observed in California.

Not surprisingly, the venue where support for never allowing smoking was highest was hospitals, and the venue where support was lowest was bars. However, Californians showed increased support for not allowing smoking in bars by 1998-99. While there was an increase from 1992-93 to 1995-96, the increase between 1995-96 and 1998-99 was even higher, which probably reflects the fact that bars went smoke-free in January 1998. Table l shows that most of the increase in support for smoke-free workplaces and restaurants occurred by 1995-96, just after the law was implemented that made most California indoor workplaces smoke-free. It is interesting that respondents did not think that restaurants should be smoke-free to the same degree as they thought some of the other venues should be. Restaurants are often the vanguard for tobacco control efforts, which may create controversy and sympathy in the public's mind for restaurant owners' pleas that they will lose business if they go smoke-free. Less publicised are data showing that restaurant sales do not decline following the imposition of a smoke-free law. ${ }^{13}$

Females were more likely to support smoke-free venues than males, and while younger adults were less likely to support such policies in 1992-93, they increased their support at a more rapid pace than older adults so that age differences were minimal by 1998-99. Perhaps youth coming of age in a more smoke-free environment begin to take it for granted that smoking should not be allowed in public settings. Demographic differences with respect to education and race/ ethnicity tended to even out much more in California than in the rest of the USA from 1992-93 to 1998-99. California used the mass media to educate the public regarding the dangers of secondhand smoke, with special spots on Asian and Hispanic television channels. Also, spots on regular channels featured African American actors. Such campaigns appear to reach a large segment of the population, regardless of educational level. ${ }^{14}$

Support for at least four smoke-free venues was highest among people with smoke-free homes, particularly Californians. It is logical that smoking restrictions in the home are associated with population attitudes about where smoking should not be allowed to a greater degree than smoking restrictions in the workplace. Home restrictions are by mutual agreement, but, for the most part, in the workplace they are imposed by statute or by the business owner. The CPS data from 1998-99 indicate that California ranks among a small group of states with respect to the highest percentages of smoke-free homes and smoke-free workplaces in the nation. While a high level of smoke-free homes, in particular, may influence Californians' attitudes regarding smoking restrictions in other venues, it is important to note that Californians without smoke-free homes showed a larger percentage increase in their attitudes than did those with smoke-free homes (table 2). This result suggests that more is driving attitude change than existing high levels of home and workplace smoking bans. Other aspects of California's comprehensive tobacco control programme, such as its media campaign and community programmes promoting anti-tobacco norms in general and smoke-free venues specifically, are likely playing important roles in changing population attitudes.

California's smokers have increased their level of support for smoke-free venues much more rapidly than former smokers and never smokers. Perhaps smokers who are subject to smoking bans at home or at work have successfully modified their behaviour to accommodate them. Thus, they are more likely to think that other smokers can cope as well and that smoking restrictions are not a hardship. In California, we have noted that an ever smaller percentage of smokers report being asked not to smoke, together with a decrease in non-smokers saying that they have asked someone not to smoke in the past year. ${ }^{15}$ This decline was greater than the decline in current smoking prevalence would imply and it suggests that smokers are becoming increasingly considerate about not smoking in the presence of nonsmokers.

In addition to adaptation by smokers and appreciation of smoke-free places by non-smokers, some of the rapid increase in support in California for smoke-free venues could be from the smoke-free workplace law itself. People are generally law abiding, and, as mentioned earlier, once this law took effect in 1995 and was extended to bars/cocktail lounges in 1998, support for these venues to be smoke-free increased notably. Whether this experience will be repeated in other states or countries is unknown.

California public health officials aim to expand their successes in protecting non-smokers and promoting antitobacco norms by building support for outdoor smoke-free venues, such as toddler play lots, bus stops, amusement parks, fairgrounds, concerts, sporting events, and indoor shared-air living venues, including apartments and condominiums. ${ }^{2}$ Not all US states or other countries are ready to restrict smoking to this degree, but perhaps they could begin to build support for smoking restrictions by focusing on protecting non-smokers from secondhand smoke in workplaces, beginning with health care venues, including outpatient clinics and eldercare facilities. Another workplace venue that would likely garner a high level of popular support is educational facilities, from daycare providers to high school campuses to college residence halls. Once the population experiences the benefits of such smoke-free venues, it may be easier to extend protection to all workplaces, including restaurants and bars. Promoting smoking restrictions in the workplace and other public places should be a cornerstone of all comprehensive tobacco control programmes.

\section{ACKNOWLEDGEMENTS}

Preparation of this article was supported by grant 9RT-0036 from the University of California Tobacco Related Disease Research Program.

\section{Authors' affiliations}

E A Gilpin, L Lee, J P Pierce, Cancer Prevention and Control Program, Cancer Center, University of California, San Diego, La Jolla, California, USA 


\section{REFERENCES}

1 Centers for Disease Control. Best practices for comprehensive tobacco control programs - August 1999. Atlanta, Georgia: Office on Smoking and Health,

National Center for Chronic Disease Prevention and Health Promotion, 1999

2 Tobacco Education Research Oversight Committee. Toward a tobacco-free California: strategies for the $21^{\text {st }}$ Century 2000-2003. Sacramento: California Department of Health Services, Tobacco Control Section, January, 2000.

3 Gilpin EA, Farkas AJ, Emery SL, et al. Clean indoor air: advances in California, 1990-1999. Am J Public Health 2002;92:785-91.

4 US Department of Health, Education and Welfare. The health consequences of smoking. A report of the Surgeon General, 1972. Washington, DC: National Clearinghouse for Smoking and Health, 1972. (DHEW Publication No (HSM) 72-7516).

5 US Department of Health and Human Services. The health consequences of involuntary smoking. A report of the Surgeon General, 1986. Rockville, Maryland: Public Health Service, Centers for Disease Control, 1986. (DHHS Publication No (CDC) 87-8398).

6 US Environmental Protection Agency. Respiratory health effects of passive smoking: lung cancer and other disorders. Washington, DC: Office of Health and Environmental Assessment, 1992. (Publication No EPA/600/6-90/ 006F).

7 California Environmental Protection Agency (CalEPA). Health effects of exposure to environmental tobacco smoke: final report. Sacramento, California: Office of Environmentall Health Hazard Assessment, 1997.
8 National Cancer Institute. Health effects of exposure to environmental tobacco smoke: the report of the California Environmental Protection Agency. Smoking and Tobacco Control Monograph No.10. Bethesda, Maryland: National Cancer institute, 1999. (NIH publication 99-4645).

9 Hansen RH. The Current Population Survey: design and methodology. Technical paper No.40. Washington DC: US Department of Commerce, Bureau of the Census, 1985.

10 US Department of Commerce. Current Population Survey. Design and methodology. Technical Paper 63. Washington DC: US Department of Commerce, Bureau of the Census, 2000.

11 Westat. WesVar 4.0 user's guide. Rockville, Maryland: Westat, 2000.

12 US Department of Health and Human Services. Tobacco use in 1986. Methods \& basic tabulations from adult use of tobacco survey. Bethesda, Maryland: US Department of Health and Human Services, Public Health Service, Centers for Disease Control, Center for Chronic Disease Prevention and Health Promotion, Office on Smoking and Health, 1990.

13 Scollo M, Lal A, Hyland A, et al. Review of the quality of studies on the economic effects of smoke-free policies on the hospitality industry. Tobacco Control 2003; 12:13-20.

14 Pierce JP, Macaskill P, Hill D. Long-term effectiveness of mass media led antismoking campaigns in Australia. Am J Pub Health 1990;80:565-9.

15 Gilpin EA, Emery SL, Farkas AJ, et al. The California Tobacco Control Program: a decade of progress, results from the California Tobacco Surveys, 1990-1999. La Jolla, California: University of California, San Diego, 2001.

\section{The lighter side}

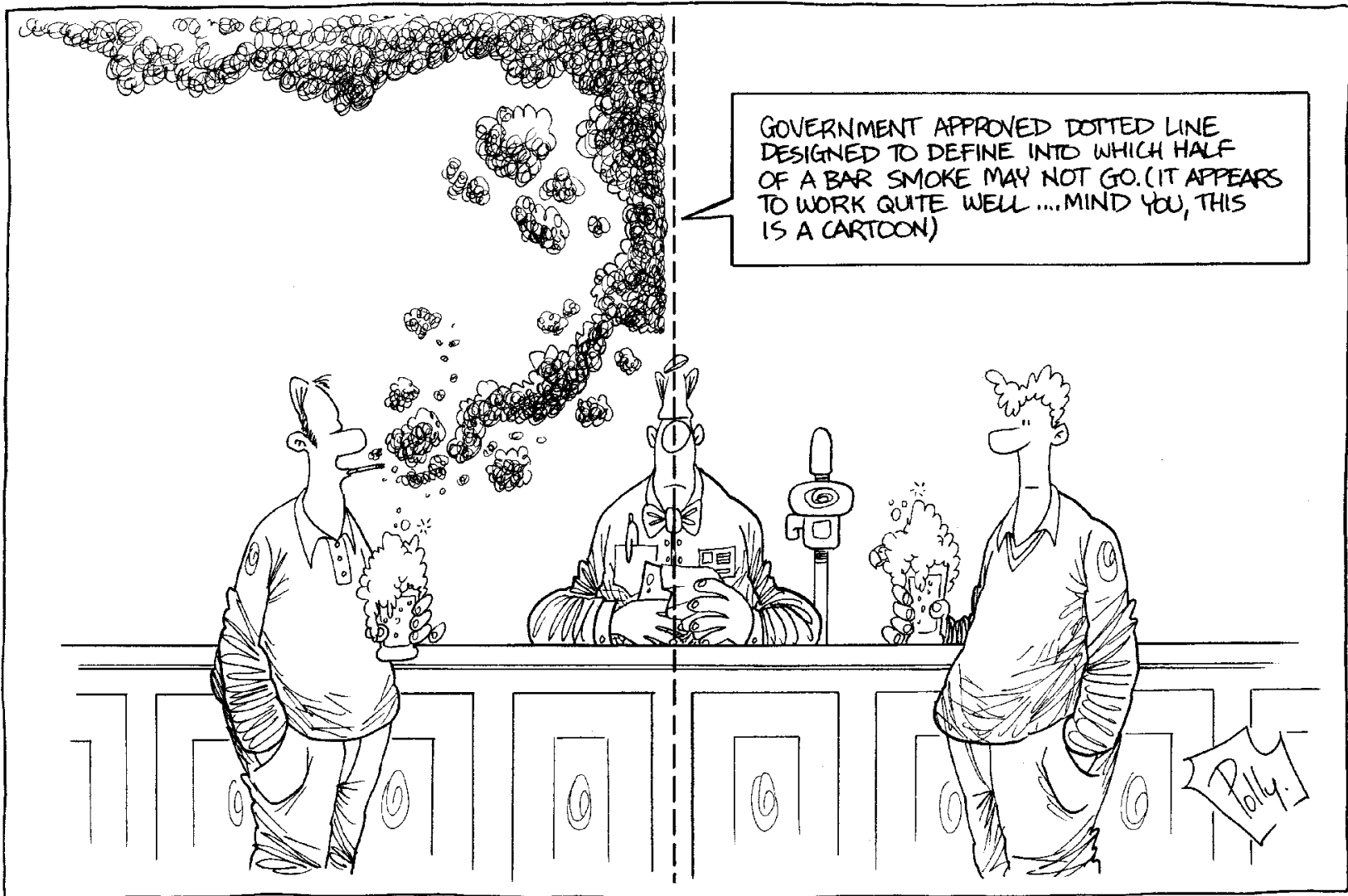

(c) John Farmer, The Mercury (Hobart, Australia). 